MARLOWE D. \& GERGEN K. J Personality and social interaction. In $G$. Lindrey and E. Aronson (Eds.), The handbook of social psychology. Vol. 3. (2nd ed.) Reading, Mass: Addison-Wesley, 1969.

RAPOPORT, A. Strategy and conscience New York: Iiarper \& Row, 1964.

TEDESCHI, J. T.. BONOMA, T.. \& LINDSKOLD, S. Threatener's reactions to prior announcement of behavioral compliance of defiance. Behavioral Science, 1970, 15,171-179.

TEDESCHI, J. T., HOR AI, J., LINDSKOLD, S., \& GAHAGAN, J. P. The effects of threat upon prevarication and compliance in social conflict. Proceedings of the $76 \mathrm{th}$ Annual Convention of the American Psychological Association, 1968, 3 , 399-400.
TEDESCHL， I, T. POWELL, J. LINDSKOLD, S, \& GAHAGAN, J.P. The patterning of "honored" promises and sex differences in social conflicts. Journal of Social Psychology, 1969, 78, 297-298.

TIKTIN, S., \& HARTUP, W. W. Sociometric status and the reinforcing effectiveness of children's peers. Journal of Experimental Child Psychology, 1965, 2, 306-315.

\section{NOTES}

1. See Rapoport (1964) for the notation used.

2. The analysis of message behavior is not included in the present report. Obtained differences were mainly from the sex factor and were consistent with those found in related $P D$ influence studies such as Tedeschi et al (1968) and Tedeschi et al (1969).

\title{
Olfactory intensity of diluted n-aliphatic alcohols*
}

\author{
KARL E. HENION† \\ University of Texas, Austin, Texas 78712
}

Psychophysical scales were constructed from magnitude estimates of 90 Os who judged the olfactory intensity of stimulus concentrations of a typical geometric dilution series prepared for each of nine alcohols in the homologous series $\mathrm{C}_{2} \cdot \mathrm{C}_{10}$. The scales, which resembled power functions with exponents from .027 to .359 , had slopes that varied inversely with carbon chain length throughout the series except for pentanol, which was out of its ordinal place in the series by one step. Results confirmed the widely held assumption of an inverse relationship.

The results of stimulus efficiency studies involving homologous alcohols have cast doubt on basing predictions about olfactory intensities at suprathreshold levels on threshold data alone (Kruger, Feldzamen, \& Miles, 1955). The unreliability of such predictions has received considerable support from the work of Engen (1965). He has emphasized that not only do threshold concentration and the intensity of undiluted alcohols vary inversely with carbon chain length, but also, apparently, dilution of an alcohol with a smaller chain length may produce a greater range of intensive discriminations than does one with a larger chain length over a given stimulus concentration range. These inverse relationships have led to the conclusion that suprathreshold predictions must be based on the natures of the appropriate psychophysical scales, primarily their slopes.

*'This research was partially supported by a grant from the University Research Institute of the Graduate School of the University of Texas. The author appreciates the valuable assistance of $G$. Terry Ross in preparing the materials and in conducting the experiment, and the cooperation of the Department of Marketing in providing space and students.

t Requests for reprints should be sent to $\mathrm{K}$ arl E. Henion, Business Administration-Economics Building No. 727, University of Texas, Austin, Texas 78712 .

In reaching this conclusion, Engen (1965) had assumed, as a result of one of his experiments, that the slopes of psychophysical intensity scales for different diluted alcohols varied inversely with chain length. The assumption was based on magnitude responses to only two alcohols, n-propanol $\left(\mathrm{C}_{3}\right)$ and n-octanol $\left(\mathrm{C}_{8}\right)$, which are relatively far apart in the homologous series of n-aliphatics. Recently, additional evidence has been provided by the work of Cain (1969), whose magnitude results with these two alcohols, and n-butanol $\left(\mathrm{C}_{4}\right)$ and $n$-hexanol $\left(\mathrm{C}_{6}\right)$ as well, demonstrated an inverse relationship. The purpose of the present investigation was to test this assumption further by determining the slopes of scales constructed from magnitude estimates for a still larger number of alcohols in the series.

\section{OBSERVERS}

Ninety undergraduates, including 38 women, volunteered to serve without pay as Os; none had participated in an olfactory experiment before. They were divided into nine random groups of 10 , and each group was assigned at random to a different odorant.

\section{ODORANTS AND APPARATUS}

These consisted of nine $n$-aliphatic homologous alcohols, from ethanol $\left(\mathrm{C}_{2}\right)$ to decanol $\left(\mathrm{C}_{10}\right)$, diluted in odorless, chromatographic-grade diethyl phthalate. Seven of the nine were of extremely high purity (viz, chromatographic or Baker-analyzed reagent grades or better), and the other two were only slightly less pure. Redistillation was not performed, since the larger distillation columns of the source companies produce an alcohol with a higher level of purity than do the smaller columns of the laboratory.

There were seven different solutions for each diluted alcohol, consisting of the following geometric dilutions prepared by means of a pipette: $1.5625 \%, 3.125 \%, 6.25 \%, 12.5 \%, 25 \%$, $50 \%$, and $100 \%$.

\section{PROCEDURE}

The experiment was conducted in a ventilated and air-conditioned room where the temperature was maintained at $25^{\circ} \mathrm{C}$. The $\mathrm{O}$ sniffed Q-tipped cotton saturated with a solution of odorant, $1.5 \mathrm{cc}$ of which were kept in $i$ ts $10 \times 75 \mathrm{~mm}$ Pyrex test tube stopped with an aluminum-foilwrapped cork. The cotton was positioned just above the surface of the odorant when not in use. The E presented to each $\mathrm{O}$ on a plastic holder, singly, the test tubes containing the seven concentrations of the assigned alcohol. Duplicate sets of comparison stimuli were used to reduce the possibility of recognition of previously presented stimuli from accidental markings on corks or test tubes.

The $O$ was exposed to his alcohol in a single $1 / 2-h$ session. Each concentration was presented twice, and different irregular orders were used for each $\mathrm{O}$. He was asked to judge the intensity of the odorant and to ignore all other attributes, to consider each comparison stimulus independently of the others, and to place the cotton at the same distance from his nose.

The O's judgments were based on magnitude estimates. He was instructed to let 10 represent the intensity of a standard, which was one of the seven concentrations and with which he was asked to become familiar. His task was to judge the intensity of each comparison stimulus, including the standard, by assigning a number to it proportionate on a ratio scale to the 10 of the standard. He could refer to the standard as often as desired, provided that there was at least a pause of $1 \mathrm{~min}$ between sniffs, which was the minimal time interval between any two sniffs in the experiment.

Since the method of magnitude estimation does not require a designated standard (Stevens, 1956; Engen, 1965), the first concentration presented was varied from one $O$ to another, letting it become his standard. The appropriateness of the 
Table 1

Scale Values of Olfactory Intensity for Nine Diluted Alcohols by Magnitude Estimation

\begin{tabular}{|c|c|c|c|c|c|c|c|c|c|}
\hline \multirow[b]{2}{*}{$\begin{array}{l}\text { Percentage of } \\
\text { Concentration }\end{array}$} & \multirow[b]{2}{*}{$\begin{array}{c}\text { Ethanol } \\
\mathrm{C}_{2} \\
\end{array}$} & \multicolumn{8}{|c|}{ Alcohol } \\
\hline & & $\begin{array}{c}\text { Propanol } \\
\mathrm{C}_{3} \\
\end{array}$ & $\begin{array}{c}\text { Butanol } \\
\mathrm{C}_{4} \\
\end{array}$ & $\begin{array}{c}\text { Pentanol } \\
\mathrm{C}_{5} \\
\end{array}$ & $\begin{array}{c}\text { Hexanol } \\
\mathrm{C}_{\mathrm{t}} \\
\end{array}$ & $\begin{array}{c}\text { Heptanol } \\
\mathrm{C}\end{array}$ & $\begin{array}{c}\text { Octanol } \\
\mathrm{C}_{s}\end{array}$ & $\begin{array}{c}\text { Nonanol } \\
\mathrm{C}_{4}\end{array}$ & $\begin{array}{c}\text { Decanol } \\
C_{1}\end{array}$ \\
\hline 1.5625 & 3.75 & 4.09 & 4.45 & 6.99 & 6.32 & 6.99 & 6.33 & 8.55 & 11.03 \\
\hline 3.125 & 4.71 & 5.01 & 5.99 & 9.99 & 7.23 & 8.58 & 7.89 & 10.84 & 9.41 \\
\hline 6.25 & 6.02 & 7.48 & 7.73 & 11.52 & 8.88 & 8.73 & 8.30 & 9.41 & 9.90 \\
\hline 12.5 & 7.89 & 10.43 & 10.73 & 11.67 & 12.15 & 10.08 & 9.54 & 10.46 & 9.43 \\
\hline 25 & 9.69 & 11.27 & 11.01 & 12.77 & 10.17 & 10.28 & 9.29 & 12.80 & 12.13 \\
\hline 50 & 13.00 & 13.32 & 11.25 & 13.80 & 15.56 & 13.81 & 10.78 & 10.52 & 10.30 \\
\hline 100 & 16.59 & 14.83 & 13.23 & 14.34 & 15.77 & 12.24 & 12.10 & 11.11 & 11.55 \\
\hline $\mathrm{SE}^{*}$ & $(2.41)$ & $(2.49)$ & $(1.81)$ & $(2.42)$ & $(2.59)$ & $(2.44)$ & $(2.19)$ & $(2.70)$ & $(2.19)$ \\
\hline
\end{tabular}

* Average of the standard errors.

procedure was demonstrated in a loudness experiment of Stevens (1956, p. 20). The number of Os who started with different concentrations were: 4 Os at $1.5625 \%, 9$ at $3.125 \%, 17$ at $6.25 \%, 25$ at $12.5 \%, 20$ at $25 \%, 10$ at $50 \%$, and 5 at $100 \%$. These various standards were also distributed fairly symmetrically across the nine alcoholic conditions.

\section{RESULTS}

Geometric means were computed from the set of 20 magnitude estimates made for each stimulus concentration in a dilution series (10 Os, two trials/concentration). This was done for each alcohol, and the results for the homologous series are presented in Table 1.

The means are plotted in Fig. 1 as a function of stimulus concentration in log coordinates. The points are well fitted by straight lines, and, except for nonanol and decanol, least-squares regressions produced no $r^{2}$ lower than .84 . These scales, obtained by magnitude estimation, conform to the power law. The exponents of the power functions, i.e., the linear slopes in Fig. 1, and the $r^{2} s$ are summarized in Table 2.

Save for $C_{5}$, which is out of place by one step in the series, the assumption by Engen (1965) of an inverse relationship between the slope of the psychophysical function for a diluted alcohol and its position in a homologous series is thus seen to be valid for a rather wide range of serial alcohols.

Table 2

Slopes and $r^{2} s$ of the Psychophysical Functions Shown in Fig. 1

\begin{tabular}{ccc}
$\begin{array}{c}\text { Carbon } \\
\text { Chain Length }\end{array}$ & Slope & $\mathrm{r}^{2}$ \\
\hline $\mathrm{C}_{2}$ & .359 & .99 \\
$\mathrm{C}_{3}$ & .321 & .95 \\
$\mathrm{C}_{4}$ & .251 & .90 \\
$\mathrm{C}_{5}$ & .150 & .84 \\
$\mathrm{C}_{6}$ & .228 & .91 \\
$\mathrm{C}_{5}$ & .144 & .89 \\
$\mathrm{C}_{3}$ & .138 & .94 \\
$\mathrm{C}_{9}$ & .053 & .39 \\
$\mathrm{C}_{10}$ & .027 & .16 \\
\hline
\end{tabular}

\section{DISCUSSION}

As expected, intensity of the alcohols with short chain lengths decreases rapidly when geometrically diluted, whereas that of the longer or oilier ones declines much more slowly, and $\mathrm{C}_{9}$ and $\mathrm{C}_{1}$ o hardly at all. There seems to be little question that dilution has a much greater effect with the shorter alcohols.

The slopes of .321 and .138 for $\mathrm{C}_{3}$ and $\mathrm{C}_{8}$, respectively, are consistent with both those of .42 and .14 obtained by Engen (1965) for the same alcohols without a prescribed modulus and those of .38 and .15 reported by Cain (1969). Moreover, $\mathrm{C}_{3}$ is stronger than $\mathrm{C}_{8}$ at the $100 \%$ concentration level in all three studies. The close agreement of the studies is another confirmation that the method of magnitude estimation works equally well without a modulus.

Implicit in the inverse relationship of the slopes is the same relationship for the subjective ranges. In this connection, it is appropriate in the present investigation to consider the ratio of the largest average sensation to the smallest as a measure of subjective range, since the stimulus concentration range is the same for each alcohol and is one typically used in olfaction, permitting useful comparisons with subjective ranges found in other studies. Except for $\mathrm{C}_{5}$ and $\mathrm{C}_{8}$, each of which is out of order by one step, but to only a moderate degree, the subjective range for the homologous series steadily decreases with chain length, beginning with $\mathrm{C}_{2}$. The average sensation evoked by $100 \%$ ethanol, which is equivalent to a mole fraction of 1.0 , is about four and one-half that evoked by the $1.5625 \%$ concentration, which is equivalent to a mole fraction of about .047.

The $r^{2} s$ vary inversely with concentration, and with the same exceptions obtaining. The lower $r^{2} s$ for $\mathrm{C}_{9}$ and $\mathrm{C}_{3}$. contrasted to the high ones for all of the other alcohols may have arisen from their slightly noisome quality. Judging the intensity of the series generally was not an unpleasant task for the Os, but some amount of unpleasantness may have made the task of isolating this attribute for these two relatively harder. Evaluation of $r^{2}$ can be considered another way. It is entirely possible that as the slope approaches zero, reversals become more frequent, thus decreasing $\mathrm{r}^{2}$, itself only a measure of how well the assumed linear regression fits the data and not necessarily how straight the function is. No plausible explanation is apparent to account for the psychophysical function of pentanol's having a slope whose numerical value is one step removed from its anticipated place in the selies.

\section{REFERENCES}

CAIN, W. S. Odor intensity: Differences in the exponent of the psychophysical function. Perception \& Psychophysics. $1969,6,349-354$

ENGEN, $T$. Psychophysical analysis of the odor intensity of homologous alcohols. Journal of Experimental Psychology, 1965, 70,611-616.

KRUGER, L. FELDZAMEN, A. N. \& MILES, W. R. Comparative olfactory intensities of the aliphatic alcohols in man. American Journal of Psychology, $1955,68,386-395$.

STEVENS, $S$, $S$. The direct estimation of sensory magnitudes-loudness. American Journal of Psychology, 1956, 69, 1-25.

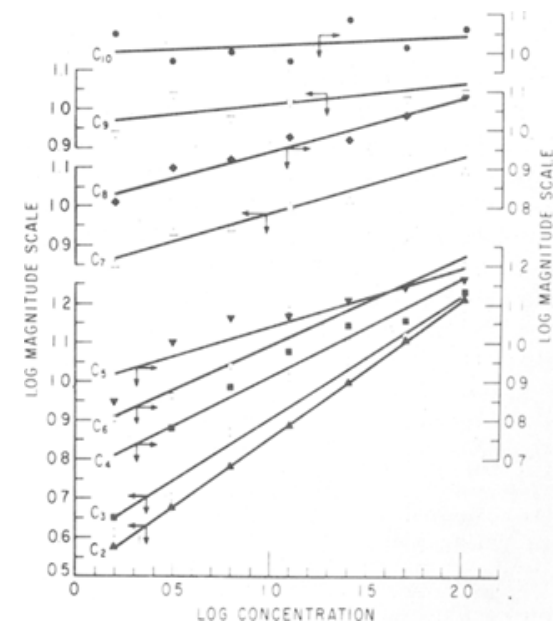

Fig. 1. Log magnitude estimation scale as a function of log concentration for alcohols $\mathrm{C}_{2}-\mathrm{C}_{9}$. 